\title{
No Role for Bacterially Produced Salicylic Acid in Rhizobacterial Induction of Systemic Resistance in Arabidopsis
}

\author{
L. X. Ran, L. C. van Loon, and P. A. H. M. Bakker
}

Faculty of Biology, Section Phytopathology, Utrecht University, P.O. Box 80084, 3508 TB Utrecht, The Netherlands. Current address of L. X. Ran: Section Forest Pathology, Forestry College, Agricultural University of Hebei, Baoding, 071001, Hebei, P. R. China.

Accepted for publication 21 July 2005.

\begin{abstract}
Ran, L. X., van Loon, L. C., and Bakker, P. A. H. M. 2005. No role for bacterially produced salicylic acid in rhizobacterial induction of systemic resistance in Arabidopsis. Phytopathology 95:1349-1355.

The role of bacterially produced salicylic acid (SA) in the induction of systemic resistance in plants by rhizobacteria is far from clear. The strong SA producer Pseudomonas fluorescens WCS374r induces resistance in radish but not in Arabidopsis thaliana, whereas application of SA leads to induction of resistance in both plant species. In this study, we compared $P$. fluorescens WCS374r with three other SA-producing fluorescent Pseudomonas strains, P. fluorescens WCS417r and CHA0r, and P. aeruginosa 7NSK2 for their abilities to produce SA under different growth conditions and to induce systemic resistance in A. thaliana against bacterial speck, caused by $P$. syringae pv. tomato. All strains produced SA in vitro, varying from $5 \mathrm{fg} \mathrm{cell}^{-1}$ for WCS417r to $>25 \mathrm{fg} \mathrm{cell}^{-1}$ for WCS374r. Addition of $200 \mu \mathrm{M} \mathrm{FeCl}_{3}$ to standard succinate medium abolished SA

CHA0r produced more SA when grown at 33 instead of $28^{\circ} \mathrm{C}$. WCS417r, CHA0r, and 7NSK2 induced systemic resistance apparently associated with their ability to produce SA, but WCS374r did not. Conversely, a mutant of 7NSK2 unable to produce SA still triggered induced systemic resistance (ISR). The possible involvement of SA in the induction of resistance was evaluated using SA-nonaccumulating transgenic NahG plants. Strains WCS417r, CHA0r, and 7NSK2 induced resistance in NahG Arabidopsis. Also, WCS374r, when grown at 33 or $36^{\circ} \mathrm{C}$, triggered ISR in these plants, but not in ethylene-insensitive ein 2 or in non-plant pathogenesis-related protein-expressing $n p r l$ mutant plants, irrespective of the growth temperature of the bacteria. These results demonstrate that, whereas WCS374r can be manipulated to trigger ISR in Arabidopsis, SA is not the primary determinant for the induction of systemic resistance against bacterial speck disease by this bacterium. Also, for the other SAproducing strains used in this study, bacterial determinants other than SA must be responsible for inducing resistance.
\end{abstract} production in all strains. Whereas the incubation temperature did not affect SA production by WCS417r and 7NSK2, strains WCS374r and

Several nonpathogenic, root-colonizing bacteria, notably of the genus Pseudomonas, are able to suppress various diseases by competition, antibiosis, or lytic enzymes directed against soilborne pathogens, or by induction of systemic resistance in the plant, extending protection to foliar pathogens (38). The induced systemic resistance (ISR) is phenotypically similar to pathogeninduced systemic acquired resistance (SAR) in that it confers an enhanced defensive capacity against diseases caused by fungi, bacteria, viruses, and nematodes. SAR is associated with the accumulation of plant pathogenesis-related proteins (PRs), some of which have been demonstrated to possess antimicrobial properties (37). Some ISR-eliciting rhizobacteria have been shown to likewise induce PRs in protected tissues, but effective ISR without accumulation of PRs or activation of $P R$ genes also has been demonstrated $(12,19,26)$.

The central signaling compound in the induction of PRs in plants is salicylic acid (SA) (33). Levels of endogenously produced SA increase both locally and systemically in incompatible plant-pathogen interactions and, to a lesser extent, in necrotizing compatible interactions, and this increase is both necessary and sufficient for SAR to develop and $P R$ genes to be activated (22, 42 ). Many bacteria that have been described to elicit ISR produce SA in vitro under iron-limiting conditions, when the compound is likely to serve as an iron-scavenging siderophore (43). When

Corresponding author: P. A. H. M. Bakker

E-mail address: P.A.H.M.Bakker@bio.uu.nl

DOI: 10.1094/PHYTO-95-1349

(c) 2005 The American Phytopathological Society
Additional keywords: root colonization.

produced in the rhizosphere, SA might elicit both ISR and PRs, and this type of ISR would be SA-dependent. However, some rhizobacteria that do not produce SA but do elicit ISR must act through an SA-independent mechanism $(27,28)$. These contrasting observations suggest that rhizobacteria may have more than one mechanism of eliciting ISR, making the significance of SA produced by rhizobacteria in the elicitation of ISR enigmatic.

There are several observations that support a role for SA in the elicitation of ISR by specific rhizobacterial strains. For instance, Pseudomonas fluorescens $\mathrm{CHA} 0$ has the ability to produce SA (24), induces PRs in tobacco, and elicits ISR against Tobacco necrosis virus (TNV) (19). Expression of the SA-biosynthetic genes of $P$. aeruginosa PAO1 in the non-SA-producer $P$. fluorescens $\mathrm{P} 3$ made this strain an elicitor of ISR in tobacco against TNV (20), demonstrating that bacterially produced SA at the root surface can trigger ISR. $P$. corrugata strain 13 and $P$. aureofaciens strain 63-28 induced systemic resistance against Pythium aphanidermatum in cucumber roots, associated with their ability to produce SA in culture. However, exogenously applied SA did not elicit ISR to cucumber root rot caused by $P$. aphanidermatum (5). Pseudomonas aeruginosa strain 7NSK2 has the ability to produce SA and elicits ISR against Tobacco mosaic virus (TMV) in tobacco (7) and against Botrytis cinerea or Colletotrichum lindemuthianum in bean $(3,9)$. By using bacterial mutants with altered SA production capacities, as well as tobacco NahG transformants in which SA-dependent responses are abolished as a result of SAhydroxylase-mediated conversion of SA to catechol, it was proven that elicitation of ISR in tobacco was SA dependent (7). However, in induced tobacco plants, the marker PR protein PR-1 was not 
detectable. This latter discrepancy could be explained by observations that tiny amounts of SA that are insufficient for inducing PRs already suffice to elicit ISR (8).

In contrast, several other reports describe that bacterial SA production and elicitation of ISR are not related. ISR elicited in tobacco against $P$. syringae pv. tabaci by the SA-producing strain Serratia marcescens 90-166 was maintained in NahG plants, suggesting that ISR by this strain is SA independent. Indeed, SAnonproducing mutants of this biocontrol strain induced resistance to the wildfire disease in tobacco to the same levels as wild-type bacteria, and likewise against anthracnose, caused by $C$. orbiculare, in cucumber (32). In strain 90-166, production of a catechol siderophore plays a key role in triggering ISR (31). A comparative analysis of strains $P$. putida WCS358, P. fluorescens WCS374, and $P$. fluorescens WCS417 indicated that both WCS358 and WCS417 elicited ISR in Arabidopsis against several fungi and bacteria, whereas WCS374 did not $(35,41)$. None of the strains induced PRs under these conditions. Nevertheless, WCS374 and WCS4 17 produced 50 and $10 \mu \mathrm{g}$ of SA ml ${ }^{-1}$ of standard succinate medium, respectively, whereas WCS358 never was found to produce SA under iron-limited conditions $(18,21)$. Thus, the nonSA-producer WCS358 did elicit ISR, whereas the strong SAproducer WCS374 did not (29). Pseudobactin, lipopolysaccharides, and flagella of WCS358 all can trigger ISR in A. thaliana $(2,25)$. In contrast, upon root colonization of radish, the ability of the three strains to elicit ISR against Fusarium oxysporum did correlate with their capacity to produce SA (i.e., both WCS374 and WCS417 elicited ISR, whereas WCS358 did not). Moreover, the level of resistance induced by the former two strains was higher when rhizosphere conditions were optimized for bacterial SA production by lowering iron availability (18).

The observation that, in Arabidopsis, the strong SA-producer WCS374 did not elicit ISR was unexpected because, upon treatment of Arabidopsis with SA, systemic resistance is induced concomitant with the activation of PR genes (40). WCS374 colonizes Arabidopsis roots to levels similar to those of the strains that do elicit ISR. Thus, it seems that our standard bioassay conditions are not conducive to the production of SA by WCS374 in the Arabidopsis rhizosphere. To investigate the extent to which SA produced by WCS374 could contribute to ISR in Arabidopsis, bacteria were grown under varying conditions of iron availability and temperature, because both factors have been described to affect the production of factors implicated in ISR $(9,18)$. For instance, in bean, ISR elicited by $P$. aeruginosa 7NSK2 was evident only when the bacterium was grown under conditions of low iron availability (9). Effects of WCS374 were compared with those of other SA-producing strains WCS417, CHA0, and 7NSK2 and to the non-SA-producing strain WCS358. To analyze whether ISR could be SA dependent, Arabidopsis NahG transformants were used in which SA-dependent ISR is abolished (6). The ethyleneinsensitive mutant ein 2 does express SA-dependent induced resistance, but SA-independent ISR, as elicited by WCS417, is lost (30). Therefore, this mutant was included to further assess a possible role for SA.

\section{MATERIALS AND METHODS}

Bacterial cultures. Bacterial strains used are listed in Table 1. All fluorescent Pseudomonas strains were grown on King's medium B (KB) agar plates (15) with or without $200 \mu \mathrm{M} \mathrm{FeCl}_{3}$ at 28 or $33^{\circ} \mathrm{C}$ for 20 to $24 \mathrm{~h}$. Strain WCS374r additionally was grown at 31 and $36^{\circ} \mathrm{C}$ for 24 and $48 \mathrm{~h}$, respectively. Bacterial cells were collected in sterile $10 \mathrm{mM} \mathrm{MgSO}$, washed twice by centrifugation at $7,600 \times g$ for $10 \mathrm{~min}$, and resuspended in $10 \mathrm{mM}$ $\mathrm{MgSO}_{4}$. Densities of the bacterial suspensions were adjusted based on their optical density at $660 \mathrm{~nm}$.

The pathogen $P$. syringae pv. tomato DC3000 (44) was cultured overnight in liquid $\mathrm{KB}$ medium at $28^{\circ} \mathrm{C}$ and shaking at $240 \mathrm{rpm}$. The suspension was washed twice with $10 \mathrm{mM} \mathrm{MgSO}_{4}$ by centrifugation at 7,600 $\times \mathrm{g}$ for $10 \mathrm{~min}$.

Analysis of in vitro production of SA by fluorescent Pseudomonas spp. Strains were cultured in $25 \mathrm{ml}$ of liquid standard succinate medium (SSM) (23) for $24 \mathrm{~h}$ at $28^{\circ} \mathrm{C}$ and $240 \mathrm{rpm}$. Then, $50 \mu \mathrm{l}$ was transferred into a $100-\mathrm{ml}$ flask containing $25 \mathrm{ml}$ of SSM (three flasks per treatment) with or without $200 \mu \mathrm{M}$ $\mathrm{FeCl}_{3}$, and incubated for $48 \mathrm{~h}$ at the desired temperature and $240 \mathrm{rpm}$. After determining the bacterial population density at $660 \mathrm{~nm}$, the culture was centrifuged at $12,000 \times \mathrm{g}$ for $10 \mathrm{~min}$, and the supernatant acidified to $\mathrm{pH} 1.5$ to 2 with $2 \mathrm{M} \mathrm{HCl}$. SA in the acidified supernatant was determined according to Meyer et al. (24), and expressed as fg per cell.

Plant cultivation and inoculation. Seed of wild-type A. thaliana accession Col-0, transgenic NahG plants, and mutants ein2 $(16,30)$ and nprl (4), all in the Col-0 background, were germinated in quartz sand, supplemented with $100 \mathrm{ml}$ of half-strength Hoagland nutrient solution (11) containing $10 \mu \mathrm{M}$ Fe-ethylenediamine di-o-hydroxyphenylacetic acid (FeEDDHA; Syngenta, Basel, Switzerland) per kilogram of sand. Two-week-old seedlings were transplanted into pots containing $100 \mathrm{~g}$ of a potting soil/sand mixture $(12: 5 \mathrm{vol} / \mathrm{vol}$, autoclaved twice for $1 \mathrm{~h}$ on alternate days), supplemented with $5 \mathrm{ml}$ of $10 \mathrm{mM} \mathrm{MgSO}_{4}$ containing fluorescent Pseudomonas spp. to a final density of $5 \times 10^{7} \mathrm{CFU}$ $\mathrm{g}^{-1}$ soil, or an equal volume of sterile $10 \mathrm{mM} \mathrm{MgSO}_{4}$ as a control. Seedlings were grown for another 3 weeks in a climate chamber with an 8-h day and 16-h night cycle at 24 and $20^{\circ} \mathrm{C}$, respectively, and at $70 \%$ relative humidity. Half-strength Hoagland solution without FeEDDHA was applied to the plants once a week, and tap water was given when needed.

When 5 weeks old, 25 plants per treatment were challenge inoculated with $P$. syringae pv. tomato. The rosette leaves of Col0 wild-type and $n p r 1$ and ein 2 mutant plants were dipped into a $P$. syringae pv. tomato suspension containing $2.5 \times 10^{7} \mathrm{CFU} \mathrm{ml}{ }^{-1}$ and $0.01 \%$ (vol/vol) Silwet L-77 (Van Meeuwen Chemicals BV, Weesp, The Netherlands). Because of the enhanced susceptibility of the NahG transformant to P. syringae pv. tomato (29), NahG plants were inoculated similarly with $2.5 \times 10^{6} \mathrm{CFU} \mathrm{ml}{ }^{-1}$. The inoculated seedlings were kept at $100 \%$ relative humidity for disease to develop. After 3 or 4 days, the percentage of leaves per plant showing chlorotic or necrotic lesions was determined.

TABLE 1. Pseudomonas strains used in this study

\begin{tabular}{|c|c|c|}
\hline Strain & Relevant characteristics ${ }^{\mathrm{a}}$ & Reference \\
\hline Pseudomonas aeruginosa 7NSK2 & Wild type; $\mathrm{Pch}^{+}, \mathrm{Pvd}^{+}, \mathrm{SA}^{+} ; \mathrm{amp}^{\mathrm{r}}, \mathrm{chl}^{\mathrm{r}}$ & 6 \\
\hline $\mathrm{KMPCH}$ & Chemical mutant of MPFM1; $\mathrm{Pch}^{-}, \mathrm{Pvd}^{-}, \mathrm{SA}^{+} ; \mathrm{amp}^{\mathrm{r}}, \mathrm{chl}^{\mathrm{r}}, \mathrm{Km}^{\mathrm{r}}$ & 6 \\
\hline MPFM1 & Tn5 mutant of 7NSK2; $\mathrm{Pch}^{+}, \mathrm{Pvd}^{-}, \mathrm{SA}^{+} ; \mathrm{amp}^{\mathrm{r}}, \mathrm{chl}^{\mathrm{r}}, \mathrm{Km}^{\mathrm{r}}$ & 6 \\
\hline MPFM1-569 & $p c h A$ replacement mutant of MPFM1; $\mathrm{Pch}^{-}, \mathrm{Pvd}^{-}, \mathrm{SA}^{-} ; \mathrm{amp}^{\mathrm{r}}, \mathrm{chl}^{\mathrm{r}}, \mathrm{Km}^{\mathrm{r}}$ & 6 \\
\hline P. fluorescens CHA0r & Isolated from tobacco rhizosphere; $\mathrm{HCN}^{+}, \mathrm{Phl}^{+}, \mathrm{Plt}^{+}, \mathrm{Pvd}^{+}, \mathrm{SA}^{+} ; \mathrm{amp}^{\mathrm{r}}$, chl' ${ }^{\mathrm{r}}$, rif & 18,34 \\
\hline P. fluorescens WCS374r & Isolated from potato rhizosphere; $\mathrm{SA}^{+}, \mathrm{amp}^{\mathrm{r}}, \mathrm{chl}^{\mathrm{r}}, \mathrm{rif}^{\mathrm{r}}$ & 10 \\
\hline P. fluorescens WCS417r & Isolated from wheat rhizosphere; $\mathrm{SA}^{+}, \mathrm{amp}^{\mathrm{r}}, \mathrm{chl}^{\mathrm{r}}$, rif $^{\mathrm{r}}$ & 17 \\
\hline P. putida WCS358r & Isolated from potato rhizosphere; $\mathrm{SA}^{-}, \mathrm{amp}^{\mathrm{r}}$, $\mathrm{chl}^{\mathrm{r}}$, rif $^{\mathrm{r}}$ & 10 \\
\hline P. syringae pv. tomato DC 3000 & Causal agent of bacterial speck; rif ${ }^{r}$ & 44 \\
\hline
\end{tabular}

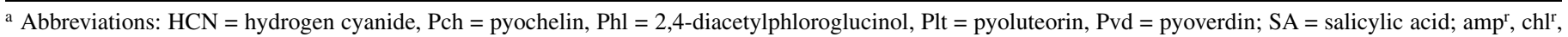

$\mathrm{Km}^{\mathrm{r}}$, and rif $^{\mathrm{r}}=$ resistant to ampicillin, chloramphenicol, kanamycin, and rifampin, respectively. 
Rhizosphere populations of fluorescent Pseudomonas spp. At the end of each experiment, roots of five plants per treatment were harvested separately and shaken vigorously for $1 \mathrm{~min}$ in $10 \mathrm{vol}\left(\mathrm{g} \mathrm{vol}^{-1}\right)$ of $10 \mathrm{mM} \mathrm{MgSO}_{4}$ with $0.5 \mathrm{~g}$ of glass beads $(0.6 \mathrm{~mm}$ in diameter). Aliquots of $100 \mu \mathrm{l}$ at proper dilutions were pipetted into 24-well tissue culture plates and $400 \mu$ of KB agar supplemented with ampicillin $\left(40 \mu \mathrm{g} \mathrm{m} \mathrm{m}^{-1}\right)$, cycloheximide $\left(100 \mu \mathrm{g} \mathrm{ml}^{-1}\right)$, and chloramphenicol $\left(13 \mu \mathrm{g} \mathrm{ml}^{-1}\right)(\mathrm{KB}+)$, at 45 to $50^{\circ} \mathrm{C}$, was added to each well. For strains WCS358r, WCS374r, WCS417r, and CHA0r, KB+ agar was supplemented with rifampin $\left(150 \mu \mathrm{g} \mathrm{ml} l^{-1}\right)$. Plates were incubated at $28^{\circ} \mathrm{C}$ for 24 to $36 \mathrm{~h}$. $P$. aeruginosa $7 \mathrm{NSK} 2$ was grown in $\mathrm{KB}+$ only and incubated at $37^{\circ} \mathrm{C}$ for 16 to $20 \mathrm{~h}$. For mutants KMPCH, MPFM1, and MPFM1-569, KB+ was supplemented with kanamycin $(200 \mu \mathrm{g}$ $\left.\mathrm{ml}^{-1}\right)$. After incubation, the colonies that had developed in each well were counted with the aid of a light microscope and the number of CFU per gram of fresh root was calculated.

Data analysis. Leaves showing necrotic or water-soaked lesions surrounded by chlorosis were scored as diseased (29). The

TABLE 2. Salicylic acid production by fluorescent Pseudomonas spp. growing at different temperatures in liquid standard succinate medium without iron ${ }^{\mathrm{a}}$

\begin{tabular}{lccr}
\hline Strain & \multicolumn{1}{c}{$28^{\circ} \mathrm{C}$} & $31^{\circ} \mathrm{C}$ & \multicolumn{1}{c}{$33^{\circ} \mathrm{C}$} \\
\hline WCS374r & $18.8 \pm 0.46$ & $27.2 \pm 0.87$ & $26.0 \pm 0.61$ \\
WCS417r & $4.5 \pm 0.17$ & nd & $5.4 \pm 0.47$ \\
CHA0r & $6.0 \pm 0.55$ & nd & $13.7 \pm 0.09$ \\
7NSK2 & $8.4 \pm 0.20$ & nd & $8.2 \pm 0.48$ \\
WCS358r & 0 & nd & nd \\
\hline
\end{tabular}

a Salicylic acid production is expressed as $\mathrm{fg}$ cell $^{-1}$ (means \pm standard error); nd $=$ not determined. percentages of diseased leaves were statistically analyzed using one-way analysis of variance (ANOVA), followed by Fisher's least significant differences test $(P \leq 0.05)$, using SPSS software (SPSS for Windows, version 8.0).

All experiments were performed at least twice and yielded comparable results.

\section{RESULTS}

SA production in vitro by Pseudomonas spp. To compare the capacity of the fluorescent Pseudomonas strains to produce SA at different temperatures, WCS374r, WCS417r, CHA0r, and 7NSK2 were grown in liquid SSM medium. Strain WCS374r hardly grew in liquid culture at $36^{\circ} \mathrm{C}$ and analysis of SA production at this temperature was not possible. Of all strains, WCS374r produced the highest level of SA, amounting to $\approx 19 \mathrm{fg} \mathrm{cell}^{-1}$ at $28^{\circ} \mathrm{C}$ and increasing to $>25 \mathrm{fg} \mathrm{cell}^{-1}$ at 31 and $33^{\circ} \mathrm{C}$ (Table 2). Temperature had no significant effect on SA production by WCS417r and 7NSK2, but CHA0r produced more than double the amount of SA at 33 compared with $28^{\circ} \mathrm{C}$. As previously observed $(18,21)$, strain WCS358 did not produce SA.

Supplementing the medium with $200 \mu \mathrm{M} \mathrm{FeCl}$ completely suppressed SA production in all producer strains (data not shown), confirming that SA production by the bacteria is iron regulated.

Effects of iron availability and temperature during bacterial growth on induction of systemic resistance. As shown previously (41), strain WCS374r, when grown at $28^{\circ} \mathrm{C}$ on ironlimited $\mathrm{KB}$ agar plates, did not induce resistance, whereas strains WCS417r, CHA0r, and 7NSK2, as well as the non-SA-producing strain WCS358, all induced significant systemic resistance in
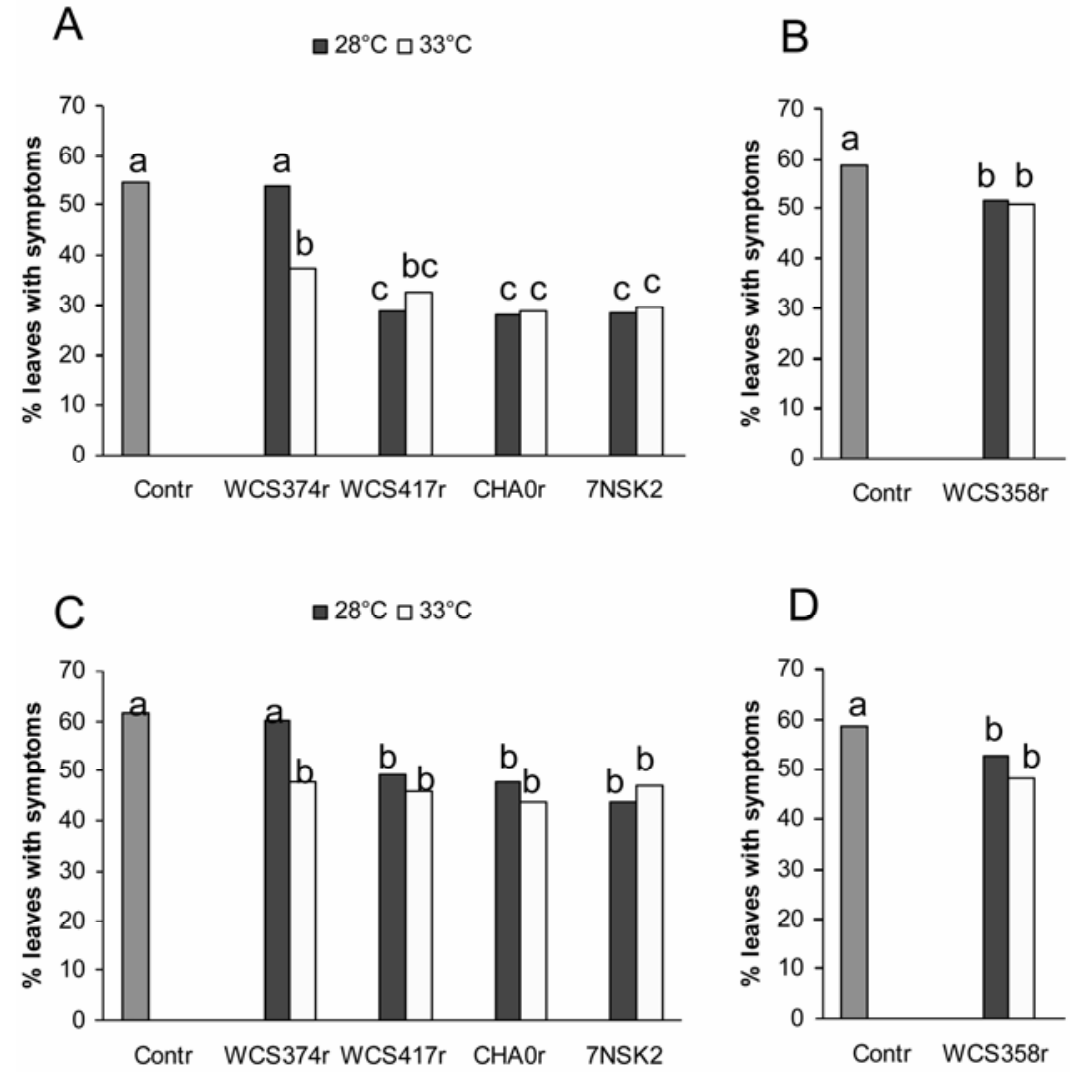

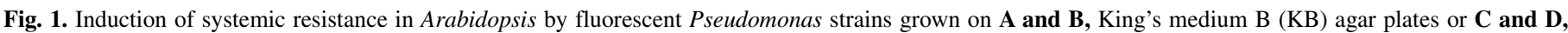

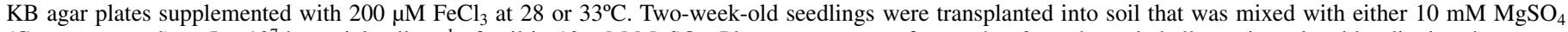

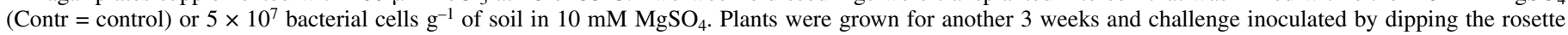

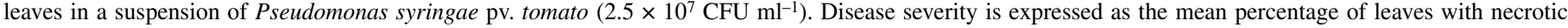

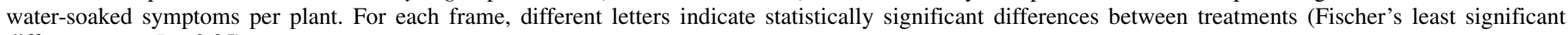
difference test; $P \leq 0.05$ ). 
Arabidopsis (Fig. 1A and B). Addition of iron to the growth medium did not alter the abilities of the strains to induce resistance (Fig. 1C and D). Increasing the temperature of growth from 28 to $33^{\circ} \mathrm{C}$ had no effect on the abilities of strains WCS417, CHA0, 7NSK2, and WCS358 to induce resistance in either the absence (Fig. 1A and B) or the presence (Fig. 1C and D) of iron. However, WCS374 became ISR-inducing when grown at $33^{\circ} \mathrm{C}$ in both the absence (Fig. 1A) or the presence (Fig. 1C) of iron. Population densities of the introduced strains in the rhizosphere of Arabidopsis varied between 6.5 and $7.0 \log \mathrm{CFU} \mathrm{g} \mathrm{g}^{-1}$ of fresh root. Incubation temperature and iron availability did not significantly influence the population densities in the rhizosphere (data not shown). Thus, the inability of strain WCS374r to induce resistance when grown at $28^{\circ} \mathrm{C}$ did not result from insufficient rhizosphere populations. Moreover, because SA production in this strain is iron regulated, the resistance induced at $33^{\circ} \mathrm{C}$ was unlikely to be the exclusive result of bacterially produced SA.

Effects of iron-regulated factors of strain 7NSK2 on elicitation of ISR. The availability of specific mutants of strain 7NSK2 allowed further investigation of the possible involvement of SA and the iron-regulated siderophores pyoverdin and pyochelin in the elicitation of ISR by this strain. Mutants MPFM1, deficient in the production of pyoverdin, $\mathrm{KMPCH}$, lacking both pyoverdin and pyochelin, and MPFM1-569, impaired in synthesis of both siderophores as well as SA, all reduced the percentage of diseased leaves to comparable extents (Fig. 2). These results demonstrate that pyoverdin, pyochelin, or SA are not necessary for the induction of ISR by 7NSK2 in Arabidopsis.

Signaling pathways in the induction of systemic resistance in Arabidopsis. To further test for an involvement of SA in the induction of systemic resistance by strains WCS417r, CHA0, and 7NSK2, the experiments were repeated using SA-non-accumulating NahG plants. As expected, strain 7NSK2 elicited significant ISR (Fig. 3), similar to that in wild-type plants (Fig. 1). Also, strains WCS417r and CHA0r induced systemic resistance in this transformant, although to a significantly lesser extent (Fig. 3). Nevertheless, it can be concluded that significant ISR is triggered by these strains independent of SA signaling.

Because induction of systemic resistance by strain WCS374r was temperature dependent (Fig. 1), its inducing activity was investigated in more detail by growing the bacterium at different temperatures and testing for ISR in wild-type, NahG-transformed, and ein2 and nprl mutant plants. The ability of WCS374r to in-

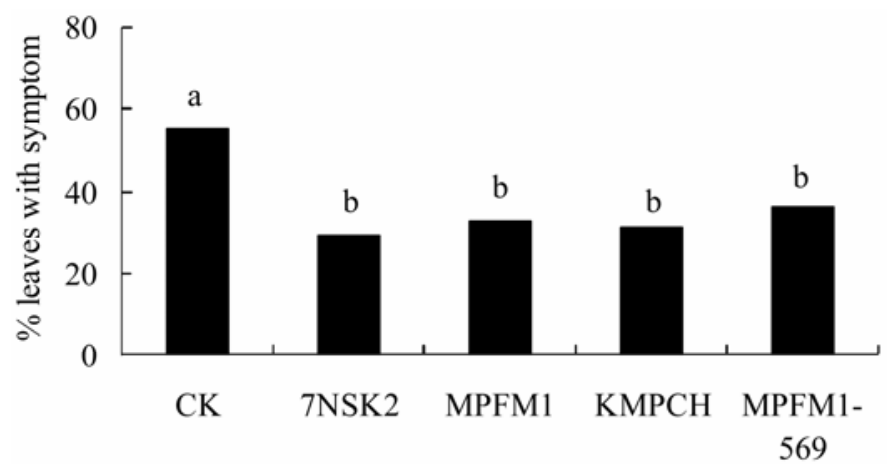

Fig. 2. Induction of systemic resistance in Arabidopsis by Pseudomonas aeruginosa strain 7NSK2 and its mutants defective in biosynthesis of pyoverdin (MPFM1), pyoverdin and pyochelin (KMPCH), and pyoverdin, pyochelin and SA (MPFM1-569). Two-week-old seedlings were transplanted into soil that was mixed with either $10 \mathrm{mM} \mathrm{MgSO}_{4}($ Contr $=$ control $)$ or $5 \times$ $10^{7}$ bacterial cells g ${ }^{-1}$ of soil in $10 \mathrm{mM} \mathrm{MgSO}_{4}$. Plants were grown for another 3 weeks and challenge inoculated by dipping the rosette leaves in a suspension of Pseudomonas syringae pv. tomato $\left(2.5 \times 10^{7} \mathrm{CFU} \mathrm{ml}^{-1}\right)$. Disease severity is expressed as the mean percentage of leaves with necrotic water-soaked symptoms per plant. For each frame, different letters indicate statistically significant differences between treatments (Fischer's least significant difference test; $P \leq 0.05)$. duce resistance increased gradually when the growth temperature of the bacteria was increased from 28 to $36^{\circ} \mathrm{C}$ (Fig. 4A). Essentially similar results were obtained in NahG plants (Fig. 4B), supporting the notion that SA produced by WCS374r grown at higher temperatures was not the main factor to induce resistance. Similar tests in ethylene-insensitive ein2 plants demonstrated that, independent of its growth temperature, WCS374r did not induce resistance (Fig. 4C). These results clearly indicate that elicitation of ISR by WCS374r in Arabidopsis requires sensitivity to ethylene. Likewise, no significant resistance was induced in the nprl mutant when WCS374 was grown at either 28 or $33^{\circ} \mathrm{C}$ (data not shown). Thus, resistance induced by WCS374r also is dependent on NPR1. The lack of resistance induction in ein2 or $n p r 1$ plants was not due to poor root colonization, because the population densities of WCS374r in the rhizosphere of the wild-type, transgenic, and mutant plants did not differ significantly in any of these assays (data not shown).

\section{DISCUSSION}

Our study focused on understanding further the contribution of the SAR-signaling compound SA in the elicitation of ISR in Arabidopsis by several Pseudomonas strains. To study a possible role of bacterially produced SA in the induction of systemic resistance in vivo, the bacteria were grown at different temperatures and iron availabilities before applying them onto the plant roots. Our assumption was that growing the bacteria at conditions that promote bacterial SA production would increase their eliciting activity.

Four of the five strains used consistently induced systemic resistance against the pathogen $P$. syringae pv. tomato. When grown under standard conditions, WCS374 did not elicit ISR. On Arabidopsis, WCS374 was the only non-ISR inducing-strain described (41); however, mutants of CHA0 that lack production of 2,4diacetylphloroglucinol also do not induce systemic resistance in Arabidopsis (13). Therefore, the ability of Pseudomonas bacteria to induce ISR in this plant species appears to be linked to specific bacterial traits. All five strains studied, with the exception of $P$. putida WCS358, had the capacity to produce SA in vitro under iron-limiting conditions. Because WCS358 does not produce SA $(18,21)$, this strain elicits ISR by an SA-independent mechanism $(2,25)$. Several lines of evidence indicate that this also applies to the other strains, which have the capacity to produce SA. Similar levels of ISR were evident in plants treated with WCS374, WCS417, CHA0, and 7NSK2 grown in the absence or presence

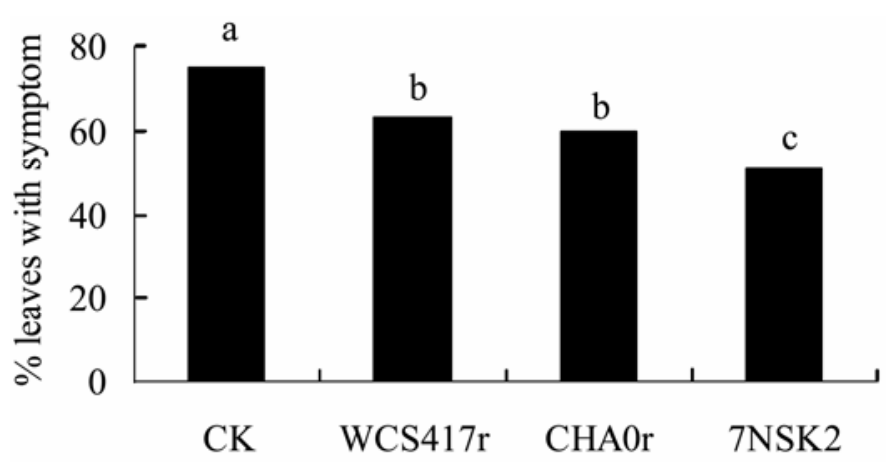

Fig. 3. Induction of systemic resistance in the NahG transformant of Arabidopsis by fluorescent Pseudomonas strains WCS417r, CHA0r, and 7NSK2. Two-week-old seedlings were transplanted into soil that was mixed with either $10 \mathrm{mM} \mathrm{MgSO}_{4}($ Contr $=$ control $)$ or $5 \times 10^{7}$ bacterial cells $\mathrm{g}^{-1}$ of soil in $10 \mathrm{mM} \mathrm{MgSO}$. Plants were grown for another 3 weeks and challenge inoculated by dipping the rosette leaves in a suspension of Pseudomonas syringae pv. tomato $\left(2.5 \times 10^{7} \mathrm{CFU} \mathrm{m} \mathrm{m}^{-1}\right)$. Disease severity is expressed as the mean percentage of leaves with necrotic water-soaked symptoms per plant. Different letters indicate statistically significant differences between treatments (Fischer's least significant difference test; $P \leq 0.05$ ). 
of iron, conditions that lead to induction and repression, respectively, of the synthesis of SA by these strains. However, it could not be excluded that iron-limiting conditions prevailed in the rhizosphere of treated plants, and that SA production occurred in situ on plant roots irrespective of previous culture conditions.

The resistance-inducing action of SA is abolished in transformed plants carrying the $N a h G$ gene (6). Testing the strains on NahG plants showed that WCS417, CHA0, and 7NSK2 still induced resistance. That the induction by 7 NSK2 was fully SA independent was borne out by the use of bacterial mutants impaired in SA or siderophore production. Like SA, siderophores are produced only under iron-limited conditions. Moreover, SA is an intermediate in the biosynthesis of the pyochelin siderophore. All mutants elicited ISR comparable with the wild type, indicating that neither SA nor the pyoverdin or pyochelin siderophores are necessary for the induction of systemic resistance by 7NSK2 in Arabidopsis. Notably, the involvement of SA in ISR elicitation by 7NSK2 appears to be plant species specific. De Meyer and Höfte (9) observed induction of resistance to gray mold in bean only when the bacterium was prepared from iron-limited $\mathrm{KB}$, but not when grown on iron-rich LB medium. Further results obtained by use of the bacterial mutants strongly suggested that SA produced by 7 NSK2 is required for the induction of systemic resistance in both bean against $B$. cinerea (9) and tobacco against TMV (7). However, it recently was demonstrated by Audenaert et al. (1) that, whereas ISR elicited by $7 \mathrm{NSK} 2$ requires the SA signaling pathway in tomato, the bacterial trigger of ISR is the combination of the antibiotic pyocyanin and the SA-containing pyochelin, rather than SA itself.

The significantly lesser resistance induced by WCS417 and CHA0 in NahG plants compared with wild-type plants is difficult to interpret, but might point to a small contribution of SA on the level of resistance attained. However, the strongly increased SA production of CHA0r grown in vitro at $33^{\circ} \mathrm{C}$ had no additional effect on its ability to elicit ISR, suggesting that SA does not contribute to the induction of systemic resistance by this strain in Arabidopsis. In contrast, in tobacco, induction of systemic resistance by CHA0 against TNV seems to be dependent on accumulation of SA (20). CHA0 can secrete a number of antimicrobial compounds, including 2,4-diacetylphloroglucinol (14). Recently, it was shown that this antibiotic can act as a determinant of ISR elicitation by this strain and that this induction occurs independently of SA (13). As for strain WCS417, Pieterse et al. $(29,30)$ previously established that WCS417r was as active in triggering ISR in Arabidopsis NahG as in wild-type plants, and that the signaling pathway in the plant leading to ISR was different from SAR and required sensitivity to ethylene.

Of the strains examined, WCS374 had by far the largest capacity to produce SA. Yet, when cultivated at $28^{\circ} \mathrm{C}$, it did not elicit ISR in Arabidopsis. Nevertheless, increasing the temperature of cultivation induced in this strain an ability to trigger ISR, associated with a $40 \%$ increase in SA production in vitro. However, SA did not seem to be involved, because the same ability was evident when the bacterium was cultured in the presence of $200 \mu \mathrm{M} \mathrm{FeCl}$, when no SA was produced, or when bioassays were conducted on NahG plants, in which SA-dependent ISR is abolished. When incubated at 28 or $31^{\circ} \mathrm{C}$, WCS374r did not trigger ISR, but this strain reduced the percentage of diseased leaves consistently in both wild-type and NahG plants when the incubation temperature was raised to 33 or $36^{\circ} \mathrm{C}$. WCS374r produced comparably high amounts of SA in vitro when grown at 31 or $33^{\circ} \mathrm{C}$. If SA was involved, one might have expected that, when grown at either of these incubation temperatures, it would have triggered ISR to similar levels. However, the difference in the level of ISR attained was significant. Thus, it has to be concluded that the increased disease resistance observed upon application of WCS374r grown at higher temperatures was not due to SA. This conclusion is further supported by the results obtained
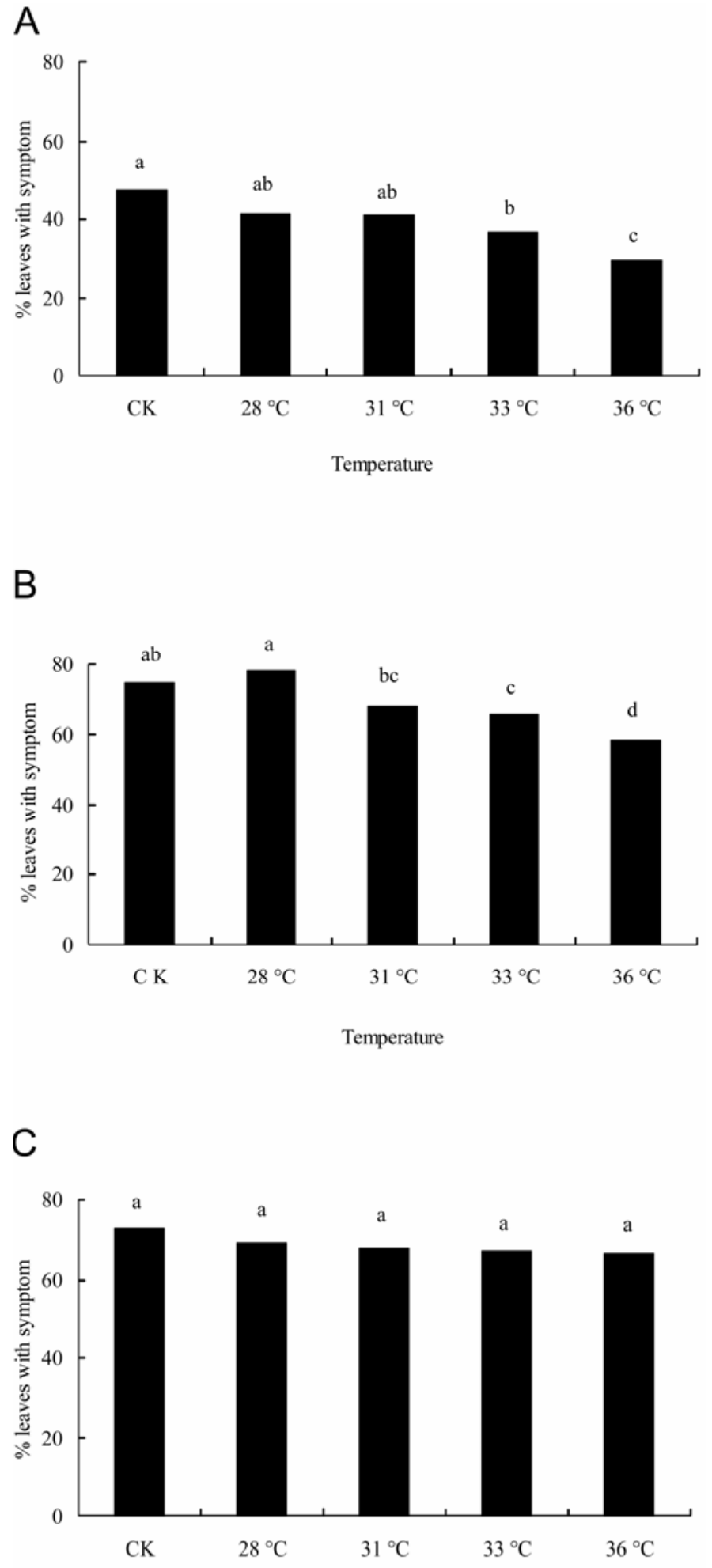

Temperature

Fig. 4. Effect of Pseudomonas fluorescens strain WCS374r grown on King's medium B agar plates at different temperatures on induction of systemic resistance in Arabidopsis A, wild-type, B, transgenic NahG, and C, mutant ein2 plants. Two-week-old seedlings were transplanted into soil that was mixed with either $10 \mathrm{mM} \mathrm{MgSO}_{4}($ Contr = control $)$ or $5 \times 10^{7}$ bacterial cells g ${ }^{-1}$ of soil in $10 \mathrm{mM} \mathrm{MgSO}$. Plants were grown for another 3 weeks and challenge inoculated by dipping the rosette leaves in a suspension of Pseudomonas syringae pv. tomato $\left(2.5 \times 10^{7} \mathrm{CFU} \mathrm{ml}^{-1}\right)$. Disease severity is expressed as the mean percentage of leaves with necrotic water-soaked symptoms per plant. For each frame, different letters indicate statistically significant differences between treatments (Fischer's least significant difference test; $P \leq 0.05$ ). 
with the ethylene-insensitive mutant ein2. In this mutant, application of SA or avirulent pathogens triggers SAR (40). However, WCS374r did not induce systemic resistance in ein2, irrespective of the incubation temperature. Also, in mutant nprl plants, WCS374r was not effective. Thus, it appears that WCS374r grown at $33^{\circ} \mathrm{C}$ triggers the same pathway as WCS417r. The incubation temperature at which the bacterial inoculum was produced may have affected other traits in WCS374, such as the lipopolysaccharides or the flagella, which have both been implicated in WCS358-mediated ISR in Arabidopsis (2,25).

Whereas, in $P$. aeruginosa 7NSK2, production of SA is linked to the synthesis of pyochelin (9), in P. fluorescens WCS374 it is associated with the production of the SA-containing siderophore pseudomonine (21). The synthesis of pseudomonine is regulated by iron availability; however, in addition, this siderophore is produced at elevated temperatures, whereas the production of the fluorescent siderophore pseudobactin is shut down at these temperatures (21). Because siderophores also have been implicated in the induction of systemic resistance $(2,39)$, effects of iron availability and temperature on the in vitro SA production by specific resistance-inducing fluorescent Pseudomonas strains may mediate elicitation of ISR in vivo through synthesis of specific siderophores. This hypothesis is supported by the iron dependency of ISR induced by CHA0 against TNV and Thielaviopsis basicola $(18,36)$ in tobacco, and by $S$. marcescens $90-166$ against $C$. orbiculare and $P$. syringae pv. tabaci in cucumber and tobacco, respectively (32). Although $S$. marcescens was capable of producing SA in vitro, SA was not the primary determinant of ISR elicited by this strain. Our results confirm those of Iavicoli et al (13) that, in Arabidopsis, CHA0 does not elicit ISR through an SAdependent mechanism. Taking into account that SA does appear to be involved in systemic resistance induced by specific strains on some plant species, our findings clearly demonstrate that plant species can differ in their reaction to resistance-inducing rhizobacteria by activating different signaling pathways leading to ISR.

\section{ACKNOWLEDGMENTS}

This research was supported by grant WB 83-169 from the Netherlands Foundation for the Advancement of Tropical Research (WOTRO) and National Natural Science Foundation of China (grant no. 39970615). We thank G. Défago and M. Höfte for providing P. fluorescens strain CHA0r and $P$. aeruginosa strain $7 \mathrm{NSK} 2$ and its mutants, respectively; I. van der Sluis and J. A. van Pelt for providing generous help in experiments; and D. M. Weller for critical comments on the manuscript.

\section{LITERATURE CITED}

1. Audenaert, K., Pattery, T., Cornelis, P., and Höfte, M. 2002. Induction of systemic resisitance to Botrytis cinerea by Pseudomonas aeruginosa 7NSK2: Role of salicylic acid, pyochelin, and pyocyanin. Mol. PlantMicrobe Interact. 15:1147-1156.

2. Bakker, P. A. H. M., Ran, L. X., Pieterse, C. M. J., and van Loon, L. C. 2003. Understanding the involvement of rhizobacteria-mediated induction of systemic resistance in biocontrol of plant diseases. Can. J. Plant Pathol. 25:5-9.

3. Bigirimana, J., and Höfte, M. 2002. Induction of systemic resistance to Colletotrichum lindemuthianum in bean by a benzothiadiazole derivative and rhizobacteria. Phytoparasitica 30:159-168.

4. Cao, H., Glazebrook, J., Clarke, J. D., Volko, S., and Dong, X. 1997. The Arabidopsis NPR1 gene that controls systemic acquired resistance encodes a novel protein containing ankyrin repeats. Cell 88:57-63.

5. Chen, C. Q., Belanger, R. R., Benhamou, N., and Paulitz, T. C. 1999. Role of salicylic acid in systemic resistance induced by Pseudomonas spp. against Pythium aphanidermatum in cucumber roots. Eur. J. Plant Pathol. 105:477-486.

6. Delaney, T. P., Uknes, S., Vernooij, B., Friedrich, L., Weyman, K., Negrotto, D., Gaffney, T., Gut-Rella, M., Kessmann, H., Ward, E., and Ryals, J. 1994. A central role of salicylic acid in plant disease resistance. Science 266:1247-1250.

7. De Meyer, G., Audenaert, K., and Höfte, M. 1999. Pseudomonas aeruginosa 7NSK2 induced systemic resistance in tobacco depends on in planta salicylic acid accumulation but is not associated with PR1a expression. Eur. J. Plant Pathol. 105:513-517.

8. De Meyer, G., Capieau, K., Audenaert, K., Buchala, A., Métraux, J. P., and Höfte, M. 1999. Nanogram amounts of salicylic acid produced by the rhizobacterium Pseudomonas aeruginosa 7NSK2 activate the systemic acquired resistance pathway in bean. Mol. Plant-Microbe Interact. 12:450-458.

9. De Meyer, G., and Höfte, M. 1997. Salicylic acid produced by the rhizobacterium Pseudomonas aeruginosa 7NSK2 induces resistance to leaf infection by Botrytis cinerea on bean. Phytopathology 87:588-593.

10. Geels, F. P., and Schippers, B. 1983. Selection of antagonistic flurorescent Pseudomonas spp. and their root colonization and persistence following treatment of seed potatoes. Phytopathol. Z. 108:193-206.

11. Hoagland, D. R., and Arnon, D. I. 1938. The water culture method for growing plants without soil. Calif. Agric. Exp. Stn. Bull. 347:36-39.

12. Hoffland, E., Pieterse, C. M. J., Bik, L., and van Pelt, J. A. 1995. Induced systemic resistance in radish is not associated with accumulation of pathogenesis-related proteins. Physiol. Mol. Plant Pathol. 46:309-320.

13. Iavicoli, A., Boutet, E., Buchala, A., and Metraux, J.-P. 2003. Induced systemic resistance in Arabidopsis thaliana in response to root inoculation with Pseudomonas fluorescens CHA0. Mol. Plant-Microbe Interact. 16:851-858.

14. Keel, C., Schnider, U., Maurhofer, M., Voisard, C., Laville, J., Burger, U., Wirthner, P., Haas, D., and Defago, G. 1992. Suppression of root diseases by Pseudomonas fluorescens CHA0: Importance of the bacterial secondary metabolite 2,4-diacetylphloroglucinol. Mol. Plant-Microbe Interact. 5:4-13.

15. King, E. O., Ward, M. K., and Raney, D. E. 1954. Two simple media for the demonstration of pyocyanin and fluorescein. J. Lab. Clin. Med. 44:301-307.

16. Knoester, M., Pieterse, C. M. J., Bol, J. F., and van Loon, L. C. 1999. Systemic resistance in Arabidopsis induced by rhizobacteria requires ethylene-dependent signaling at the site of application. Mol. PlantMicrobe Interact. 12:720-727.

17. Lamers, J. G., Schippers, B., and Geels, F. P. 1988. Soil-borne diseases of wheat in the Netherlands and results of seed bacterization with pseudomonads against Gaeumannomyces graminis var. tritici, associated with disease resistance. Pages 134-139 in: Cereal Breeding Related to Integrated Cereal Production. M. L. Jorna and L. A. J. Slootmaker, eds. Pudoc, Wageningen, The Netherlands.

18. Leeman, M., Den Ouden, F. M., van Pelt, J. A., Dirkx, F. P. M., Steijl, H., Bakker, P. A. H. M., and Schippers, B. 1996. Iron availability affects induction of systemic resistance to fusarium wilt of radish by Pseudomonas fluorescens. Phytopathology 86:149-155.

19. Maurhofer, M., Hase, C., Meuwly, P., Métraux, J. P., and Défago, G. 1994. Induction of systemic resistance of tobacco to tobacco necrosis virus by the root-colonizing Pseudomonas fluorescens strain CHA0: Influence of the gacA gene and of pyoverdine production. Phytopathology 84:139-146.

20. Maurhofer, M., Reimmann, C., Schmidli-Sacherer, P., Heeb, S., Haas, D., and Défago, G. 1998. Salicylic acid biosynthetic genes expressed in Pseudomonas fluorescens strain P3 improve the induction of systemic resistance in tobacco against tobacco necrosis virus. Phytopathology 88:678-684

21. Mercado-Blanco, J., van der Drift, K. M. G. M., Olsson, P. E., ThomasOates, J. E., van Loon, L. C., and Bakker, P. A. H. M. 2001. Analysis of the pmsCEAB gene cluster involved in biosynthesis of salicylic acid and the siderophore pseudomonine in the biocontrol strain Pseudomonas fluorescens WCS374. J. Bacteriol. 183:1909-1920.

22. Métraux, J. P. 2001. Systemic acquired resistance and salicylic acid: Current state of knowledge. Eur. J. Plant Pathol. 107:13-18.

23. Meyer, J. M., and Abdallah, M. A. 1978. The fluorescent pigment of Pseudomonas fluorescens: Biosynthesis, purification and physicochemical properties. J. Gen. Microbiol. 107:319-328.

24. Meyer, J. M., Azelvandre, P., and Georges, C. 1992. Iron metabolism in Pseudomonas: Salicylic acid, a siderophore of Pseudomonas fluorescens CHA0. Biofactors 4:23-27.

25. Meziane, H., van der Sluis, I., van Loon, L. C., Höfte, M., and Bakker, P. A. H. M. 2005. Determinants of Pseudomonas putida WCS358 involved in inducing systemic resistance in plants. Mol. Plant Pathol. 6:177-185.

26. Park, K. S., and Kloepper, J. W. 2000. Activation of PR-1a promoter by rhizobacteria that induce systemic resistance in tobacco against Pseudomonas syringae pv. tabaci. Biol. Control 18:2-9.

27. Pieterse, C. M. J., and van Loon, L. C. 1999. Salicylic acid-independent plant defense pathways. Trends Plant Sci. 4:52-58.

28. Pieterse, C. M. J., van Pelt, J. A., van Wees, S. C. M., Ton, J., LéonKloosterziel, K. M., Keurentjes, J. J. B., Verhagen, B. W. M., Knoester, M., van der Sluis, I., Bakker, P. A. H. M., and van Loon, L. C. 2001. Rhizobacteria-mediated induced systemic resistance: Triggering, signalling, and expression. Eur. J. Plant Pathol. 107:51-61. 
29. Pieterse, C. M. J., van Wees, S. C. M., Hoffland, E., van Pelt, J. A., and van Loon, L. C. 1996. Systemic resistance in Arabidopsis induced by biocontrol bacteria is independent of salicylic acid accumulation and pathogenesis-related gene expression. Plant Cell 8:1225-1237.

30. Pieterse, C. M. J., van Wees, S. C. M., van Pelt, J. A., Knoester, M., Laan, R., Gerrits, N., Weisbeek, P. J., and van Loon, L. C. 1998. A novel signaling pathway controlling induced systemic resistance in Arabidopsis. Plant Cell 10:1571-1580.

31. Press, C. M., Loper, J. E., and Kloepper, J. W. 2001. Role of iron in rhizobacteria-mediated induced systemic resistance of cucumber. Phytopathology 91:593-598

32. Press, C. M., Wilson, M., Tuzun, S., and Kloepper, J. W. 1997. Salicylic acid produced by Serratia marcescens 90-166 is not the primary determinant of induced systemic resistance in cucumber or tobacco. Mol. Plant-Microbe Interact. 10:761-768.

33. Sticher, L., Mauch-Mani, B., and Métraux, J.-P. 1997. Systemic acquired resistance. Annu. Rev. Phytopathol. 35:235-270.

34. Stutz, E. W., Défago, G., and Kern, H. 1986. Naturally occuring fluorescent pseudomonads involved in suppression of black root rot of tobacco. Phytopathology 76:181-185.

35. Ton, J., van Pelt, J. A., van Loon, L. C., and Pieterse, C. M. J. 2002. Differential effectiveness of salicylate-dependent and jasmonate/ethylenedependent induced resistance in Arabidopsis. Mol. Plant-Microbe Interact. 15:27-34

36. Troxler, J., Berling, C.-H., Moënne-Loccoz, Y., Keel, C., and Défago, G. 1997. Interactions between the biocontrol agent Pseudomonas fluorescens CHA0 and Thielaviopsis basicola in tobacco roots observed by immunofluorescence microscopy. Plant Pathol. 46:62-71.
37. van Loon, L. C. 1997. Induced resistance in plants and the role of pathogenesis-related proteins. Eur. J. Plant Pathol. 103:753-765.

38. van Loon, L. C., and Bakker, P. A. H. M. 2003. Signalling in rhizobacteria-plant interactions. Pages 297-330 in: Root Ecology. H. de Kroon and E. J. W. Visser, eds. Springer-Verlag, Berlin.

39. van Loon, L. C., Bakker, P. A. H. M., and Pieterse, C. M. J. 1998. Systemic resistance induced by rhizosphere bacteria. Annu. Rev. Phytopathol. 36:453-483.

40. van Wees, S. C. M., Luijendijk, M., Smoorenburg, I., van Loon, L. C., and Pieterse, C. M. J. 1999. Rhizobacteria-mediated induced systemic resistance (ISR) in Arabidopsis is not associated with a direct effect on expression of known defense-related genes, but stimulates the expression of the jasmonate-inducible gene Atvsp upon challenge. Plant Mol. Biol. 41:537-549.

41. van Wees, S. C. M., Pieterse, C. M. J., Trijssenaar, A., van't Westende, Y. A. M., Hartog, F., and van Loon, L. C. 1997. Differential induction of systemic resistance in Arabidopsis by biocontrol bacteria. Mol. PlantMicrobe Interact. 10:716-724.

42. Vernooij, B., Friedrich, L., Morse, A., Reist, R., Kolditz-Jawhar, R., Ward, E., Uknes, S., Kessman, H., and Ryals, J. 1994. Salicylic acid is not the translocated signal responsible for inducing systemic acquired resistance but is required in signal transduction. Plant Cell 6:959-965.

43. Visca, P., Ciervo, A., Sanfilippo, V., and Orsi, N. 1993. Iron-regulated salicylate synthesis by Pseudomonas spp. J. Gen. Microbiol. 139:1995-2001.

44. Whalen, M. C., Innes, R. W., Bent, A. F., and Staskawicz, B. J. 1991 Identification of Pseudomonas syringae pathogens of Arabidopsis and a bacterial locus determining avirulence on both Arabidopsis and soybean. Plant Cell 3:49-59. 